\title{
REVIEW
}

\section{Emergency Stop Device for Hand-fed Threshing on Head- feeding Combine Harvesters toward Safety of Farm Work}

\author{
Hirofumi YAMASAKI'*, Hirokatsu SHITO' ${ }^{1}$, Mitsuhiro HORIO', Ei SEKI', \\ Shunsuke OKADA ${ }^{1}$, Muneki TOMITA ${ }^{1}$, Yutaka KIKUCHI ${ }^{1}$, \\ Kenichiro TAKEUCHI ${ }^{2}$, Masayuki TAKAGI ${ }^{3}$, Yohichi AGAWA ${ }^{4}$ and \\ Toushi FURUTA ${ }^{5}$ \\ ${ }^{1}$ Institute of Agricultural Machinery, National Agriculture and Food Research Organization \\ (Saitama, Saitama 331-8537, Japan) \\ ${ }^{2}$ Combine-Harvester Engineering Department, ISEKI \& Co., Ltd (Iyo, Ehime 791-2193, Japan) \\ ${ }^{3}$ Combine Harvester Engineering Department, KUBOTA Corporation (Sakai, Osaka 590-0823, \\ Japan) \\ ${ }^{4}$ Development \& Design Administration Division, Mitsubishi Mahindra Agricultural Machinery \\ Co., Ltd. (Matsue, Shimane 699-0195, Japan) \\ ${ }^{5}$ Development Management Division, Agricultural Operations Business, YANMAR Co., Ltd. \\ (Maibara, Shiga 521-8511, Japan)
}

\begin{abstract}
In order to avoid severe injuries in the event of entanglement accidents during hand-fed threshing by use of head-feeding combine harvesters, we studied here the conditions required for the machinery to be developed, while obtaining farmers' opinions and attitudes toward hand-fed threshing and measurement of lifting force by female users. To satisfy these conditions, we developed prototypes additionally equipped with an opening function of either the threshing drum cover or the pinching rod, and thereby verified ability to allow users to pull out the entangled hand with ease. We completed research and development in 2013, and current models of head-feeding combine harvesters equipped with this device are commercialized by four agricultural machinery manufacturers in Japan, spreading more than 6,000 units of 21 models.
\end{abstract}

Discipline: Agricultural machinery

Additional key words: safety device, feed chain, lifting force, pinching rod, threshing drum

\section{Introduction}

The fatal and injury accident rate in farm labor of Japan is high. Based on the data in the Industrial Accident Compensation Insurance Benefits and other sources in 2011, rate of injuries and deaths per one thousand farmers was then as high as 8.8 (injuries here should involve four days and longer of doctor's visit), which is higher than the rate of 2.1 of all industries, and 5.2 of construction industry (Ministry of Health, Labour and Welfare 2012). Among farm labor accidents, the number of fatal and injury accidents caused by agricultural machinery is big, and if we focus on types of farm machinery, accidents are worst triggered by mowers (mainly brush cutters), followed by riding tractors, and (mainly head-feeding) combine harvesters (Japan Institute of Rural Medicine 2003). As for brush cutters and riding tractors, various benchmarks have been additionally applied in Safety Judgment carried out by the Institute of Agricultural Machinery (hereinafter referred to as IAM), the authorized safety test institution in Japan, based upon actual cases of accidents. For head-feeding combine harvesters, on the other hand, the only big additional standard was in 1999 , that being to equip the harvesters

This paper reports the results obtained in the joint project on "the Project for the Urgent Development of Agricultural Machinery" sponsored by the Ministry of Agriculture, Forestry and Fisheries (hereinafter referred to as MAFF).

*Corresponding author: e-mail h_yamasaki@affrc.go.jp

Received 18 July 2018; accepted 13 October 2018. 
with an emergency stop device for the prime mover that was within an easy reach in case of "hand-fed threshing" (Fig. 1). "Hand-fed threshing" is a threshing work in which manually harvested rice straws are supplied to the feed chain. No further change has been made since then, which suggests further requirements for mechanical improvements to reduce injuries. In this research, therefore, out of three types of machinery involving many injury cases, we put our focus on head-feeding combine harvesters.

We can pick up two reasons for the higher frequency of accidents involving head-feeding combine harvesters in Japan. The first is the impact of aging in farm labor. As of 2016, the ratio of elderly at the age of 60 and older of deaths in farm labor accidents was as high as $91.3 \%$, which significantly raised from $59.9 \%$ as of 1990 (MAFF 2007, MAFF 2018). In development of any agricultural machinery, elderly users should be well considered.

The second reason is the unavoidable nature of farm labor like hand-fed threshing that is done close to moving parts such as cutting and conveying unit, threshing unit, and straw disposal unit, to which laborers normally do not come close. As was stated previously, an emergency stop device is indeed equipped that aims at reduction of accidents in hand-fed threshing, but an inertial motion of the feed chain or the threshing drum even after activation of the emergency stop operation would end up with serious injury when users' hands are entangled in the threshing drum due to unavailability of an immediate stop. Concerning this aspect, frequency of accidents involving moving parts of head-feeding combine harvester were pointed out (Tomita et al. 2015).

Also, as for hand-fed threshing, in case of entanglement accidents, laborers would try by use of the emergency stop device to release the entangled hand by opening the threshing drum cover after stopping the

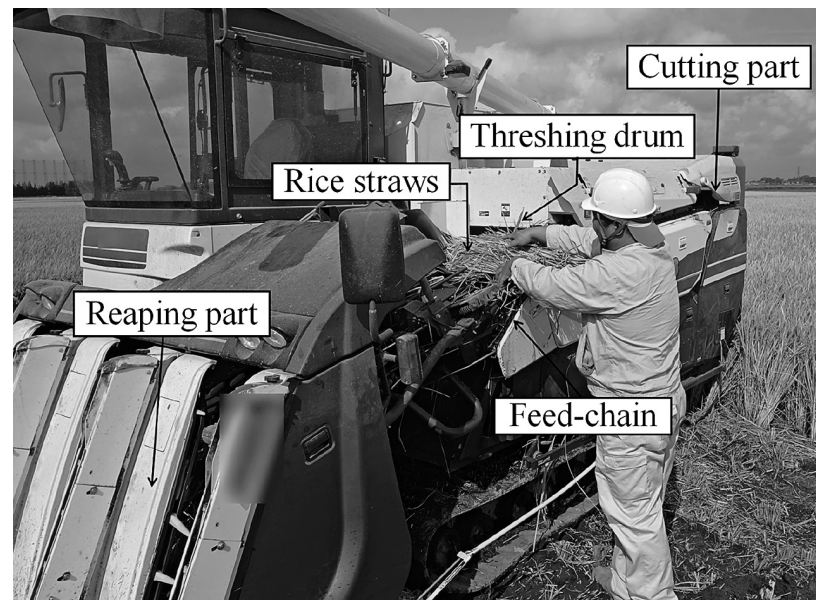

Fig. 1. Hand-fed threshing on head-feeding combine harvesters machinery. Due to entanglement, however, laborers should handle the threshing drum cover opening lever with single hand. With regard to the actual situations of agricultural machinery users and handling devices, some commercialized head-feeding combine harvesters (hereinafter referred to as "commercialized models") are reported to require an excessive force for female users to handle the brake pedal (Tomita et al. 2013). If so, required force for the threshing drum cover opening lever of commercialized models could also be too much in excess for female users, and, moreover, the opening lever should be handled with a single hand in case of an entanglement accident.

Taking all the above factors into consideration, in order to avoid severe accidents in hand-fed threshing work by use of head-feeding combine harvester, we firstly collected actual cases of hand-fed threshing works through questionnaire survey. Secondly, we studied on facts of the emergency stop button and the threshing drum cover opening lever equipped on commercialized models in Japan and measured lifting force by female users. Based on these results, we have developed an emergency stop device for hand-fed threshing, considering also use by elderly females. The report also covers provisions for the future.

\section{Facts of hand-fed threshing by use of head- feeding combine harvesters and survey on accidents and incidents (Yamasaki 2016)}

\section{Means of survey}

To clarify facts of hand-fed threshing and experiences of danger in hand-fed threshing works, we carried out a survey by posting a questionnaire form to 1,200 farming holds throughout Japan (qualified operators of agricultural machines and nearby farmers). Survey items cover age, sex, farm management scale, field environment, fact-finding on practice of hand-fed threshing, opinions and attitudes on hand-fed threshing for the future, experience of entanglement accidents or incidents (narrow-escape cases) during hand-fed threshing work, as well as surrounding situations in such cases.

\section{Results and considerations}

(1) Facts of hand-fed threshing works

Table 1 shows profiles of survey respondents and Table 2 shows the results of fact-finding on the practice of hand-fed threshing. Regarding practice of hand-fed threshing, $78 \%$ of the total respondents replied at the time of study that they were doing it. As for reason(s) of handfed threshing, as many as $78 \%$ of respondents replied that 
"there are some parts beyond reach of head-feeding combine harvesters," indicating difficulty of complete harvesting with machinery alone, although manual harvested area is reduced due to spreading of shoveling function (while this function is enacted, the vehicle does not move forward even if the main transmission lever is tilted forward, and harvesting as well as the conveying unit work to enable harvest works covering every corner of the field). In terms of their intention to continue handfed threshing, $72 \%$ of the respondents replied that "we continue because it is indispensable."

(2) Experiences of accidents and incidents in hand-fed threshing work

Table 3 shows breakdown of sex, age, and height among respondents who experienced accidents and incidents during hand-fed threshing work. The number of respondents who replied that he/she "was involved or nearly was involved in" entanglement accidents / incidents into the threshing unit during hand-fed threshing work reached as many as 58 cases, including the cases in which victims were respondent's acquaintance or co-worker. This brought us a finding that quite a few farmers take it as a lesson to recognize the risk of handfed threshing work.

Table 4 shows the survey results on experiences of accidents and incidents in hand-fed threshing work. Among respondents who experienced accidents, 33\% replied either "a little less visible" or "poorly visible" about visibility of the emergency stop button on their machinery. We presumed this poor visibility was due to the color of the button which, with the body color of the

Table 1. Profiles of survey respondents

\begin{tabular}{|c|c|}
\hline \multicolumn{2}{|c|}{ Planted area of rice fields (numeric entry: $n=237$ ) } \\
\hline$\sim 0.99$ ha & $14 \%$ \\
\hline $1 \sim 4.9$ ha & $36 \%$ \\
\hline $5 \sim 9.9$ ha & $13 \%$ \\
\hline 10 ha & $37 \%$ \\
\hline \multicolumn{2}{|l|}{$\begin{array}{l}\text { Shape of fields owned by respondents } \\
\text { (multiple choice: } \mathrm{n}=246 \text { ) }\end{array}$} \\
\hline Mostly rectangular & $14 \%$ \\
\hline Some are transformational & $36 \%$ \\
\hline More transformational than rectangular & $13 \%$ \\
\hline Mostly transformational & $37 \%$ \\
\hline \multicolumn{2}{|c|}{$\begin{array}{l}\text { Number of years in use of his / her combine harvesters } \\
\text { (numeric entry: } n=236 \text { ) }\end{array}$} \\
\hline$\sim 5$ years & $49 \%$ \\
\hline $6 \sim 9$ years & $37 \%$ \\
\hline 10 years $\sim$ & $23 \%$ \\
\hline
\end{tabular}

Table 2. Fact-finding on practice of hand-fed threshing

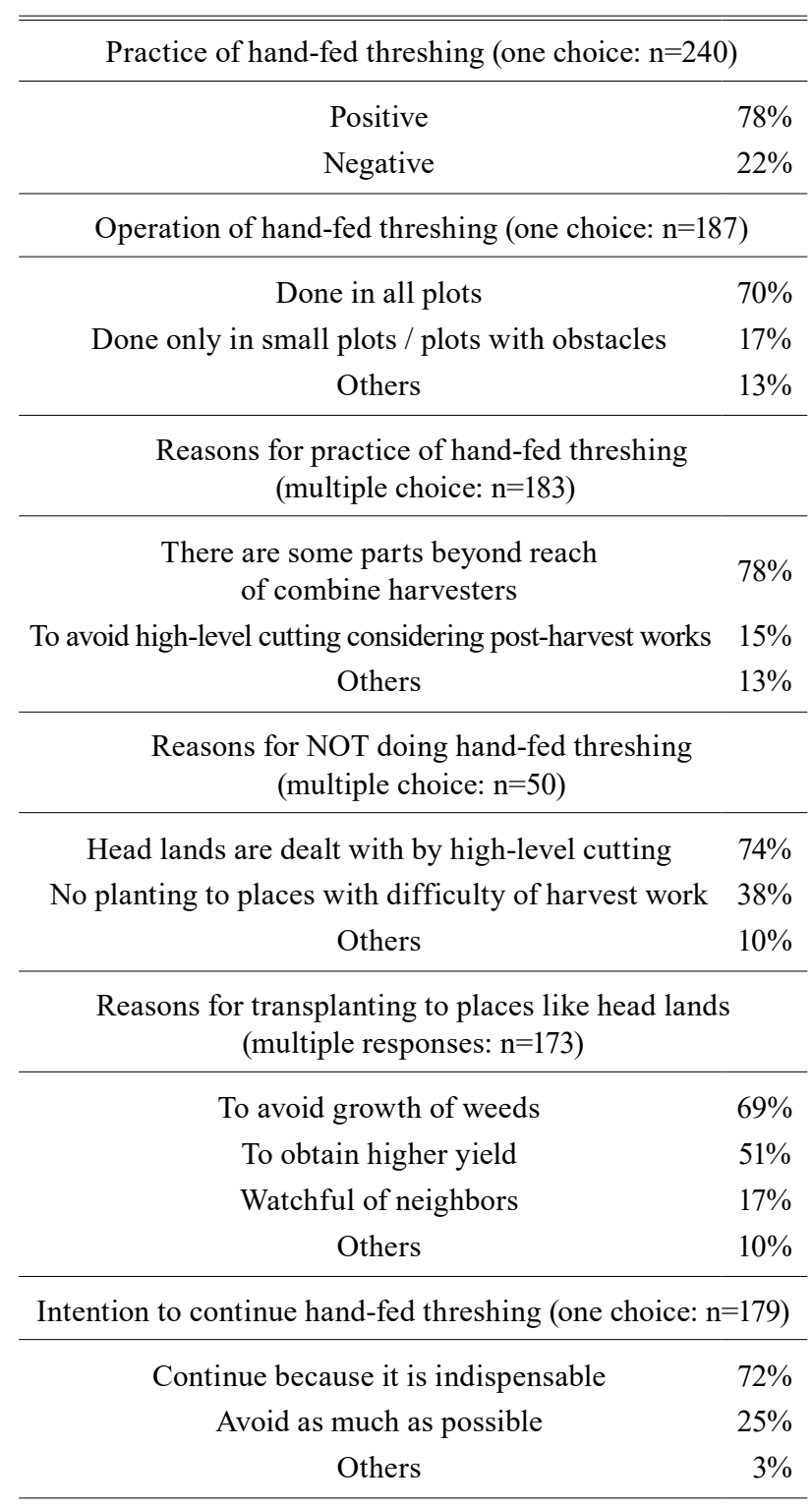

\section{Table 3. Breakdown of respondents who experienced accidents and incidents during hand-fed threshing}

\begin{tabular}{ccc}
\hline \hline \multirow{2}{*}{ Sex } & Male & $92 \%$ \\
& Female & $8 \%$ \\
\hline \multirow{2}{*}{ Age } & age $<39$ & $10 \%$ \\
& $40 \leqq$ age $<59$ & $33 \%$ \\
& $60 \leqq$ age & $57 \%$ \\
\cline { 2 - 3 } & Average & 57 \\
\hline Height $(\mathrm{cm})$ & height $<159$ & $13 \%$ \\
& $160 \leqq$ height $<169$ & $52 \%$ \\
& $170 \leqq$ height & $35 \%$ \\
\cline { 2 - 3 } & Average & $164 \mathrm{~cm}$ \\
\hline
\end{tabular}


machinery, was difficult to be distinguished.

As for the degree of injury when the event ended up with an entanglement accident, $71 \%$ of the respondents replied that the injury required either hospital visits or hospitalization, of which as high as $46 \%$ replied that they still had after effect(s). We consider, therefore, with a high probability that in case of an entanglement accident during hand-fed threshing work, the user would suffer from an injury that disturbs his/her farm management. Regarding the difference between left and right about the injured hands, $83 \%$ of the respondents replied that the injured hand was right in the questionnaire survey we carried out. However, according to our analysis picked up from injury accident surveys conducted by MAFF, Japan, from Japanese Fiscal Years 1999-2002 (6,427 cases in

Table 4. Survey results on experiences of accidents and incidents in hand-fed threshing work

\begin{tabular}{cc}
\hline Visibility of the emergency stop button (one choice: $\mathrm{n}=33$ ) \\
\hline Well visible from hand-fed threshing position & $48 \%$ \\
A less visible from hand-fed threshing position & $21 \%$ \\
Poorly visible from hand-fed threshing position & $12 \%$ \\
Others & $18 \%$ \\
\hline Cause of entanglement or narrow-escape (one choice: $\mathrm{n}=49$ ) \\
\hline Involvement of glove(s) into the feed chain & $24 \%$ \\
Involvement of clothes into the feed chain & $16 \%$ \\
Entanglement during work to remove clogged straws & $18 \%$ \\
Entanglement during work to remove residues & $20 \%$ \\
at the entrance of threshing unit & $12 \%$ \\
Unknown & $8 \%$ \\
\hline Others & \\
\hline Entangled part of the body (one choice: $\mathrm{n}=33$ ) & \\
\hline Finger(s) & $52 \%$ \\
Palm & $15 \%$ \\
Wrist & $15 \%$ \\
Lower arm & $9 \%$ \\
\hline Upper arm & \\
\hline
\end{tabular}

\begin{tabular}{cc}
\hline \multicolumn{2}{c}{ Degree of injury (one choice: $\mathrm{n}=28$ ) } \\
\hline No hospital visits required & $25 \%$ \\
Hospital visits required & $11 \%$ \\
Hospitalization required (without after effect(s)) & $18 \%$ \\
Hospitalization required (with after effect(s)) & $46 \%$ \\
\hline Right / left of the entangled / nearly entangled hand \\
(one choice: $\mathrm{n}=47$ ) \\
\hline Right & $83 \%$ \\
Left & $17 \%$ \\
\hline
\end{tabular}

four years) on the cases of head-feeding combine harvesters, the number of injuries involving the right hand was five, while the left was 18 , and 28 injuries were found unknown. The result of this analysis was different from the aforementioned questionnaire result, finding more left hand injuries. Therefore, we cannot ignore left hand injuries in accidents and incidents in hand-fed threshing work.

\section{Measurement of lifting force by female users (Yamasaki 2017)}

\section{Means of the test}

We conducted a test to clarify an appropriate range of force to handle the threshing drum cover opening lever suitable for female users to do so with a single hand by picking up 37 female subjects (Table 5). We conducted a body measurement on each subject to measure "acromiale height" as well as "elbow-grip length" of both right and left hands (Fig. 2). We defined the "baseline height" as the total of acromiale height and elbow-grip length, and set seven different grip points for the measuring device shown in Figure 3 by adding six more positions; namely, $\pm 5 \%, \pm 10 \%, \pm 15 \%$ compared with the baseline height to diversify the grip heights. The subjects used both their right and left hands to lift up the grip, and the maximum load of each and every position was measured by using a loadcell (LSM-B-SA1, Kyowa Electronic Instruments Co., Ltd.), by which we secured 14 test groups.

Also, in order to clarify issues of threshing drum cover opening levers equipped to conventionally commercialized head-feeding combine harvesters, we conducted a study on the handling force as well as installed heights of threshing drum cover opening levers on commercialized models. Measurement in terms of the

Table 5. Breakdown of subjects measuring the force of vertical lifting experienced accidents and incidents during hand-fed threshing

\begin{tabular}{|c|c|c|}
\hline \multirow{4}{*}{ Age } & age $<39$ & $22 \%$ \\
\hline & $40 \leqq$ age $<59$ & $59 \%$ \\
\hline & $60 \leqq$ age & $19 \%$ \\
\hline & Average & 51 \\
\hline \multirow{4}{*}{ Height (cm) } & Height $<159$ & $13 \%$ \\
\hline & $160 \leqq$ height $<169$ & $52 \%$ \\
\hline & $170 \leqq$ height & $35 \%$ \\
\hline & Average & $164 \mathrm{~cm}$ \\
\hline Baseline height $(\mathrm{cm})$ & Average & $160 \mathrm{~cm}$ \\
\hline
\end{tabular}


handling force for threshing drum cover opening lever, together with the ground clearance of the center part of the lever was conducted, for which measurement of 22 commercialized models in total that satisfied the Safety Judgment implemented by IAM (for two to six rows, and satisfied the same judgment in 1995-2010) was done. As for the handling force of the threshing drum cover opening levers, we applied a push-pull gage (DS2-500N, IMADA Co., Ltd.) to measure the force till the opening of the threshing drum covers, and picked up the average value of three times measurement. In case there are two opening levers at both front and back parts of the threshing drum cover, we recorded the bigger values.

\section{Results and considerations}

The ratio of testing subjects whose minimum value in 14 test groups exceeded $100 \mathrm{~N}$ was limited to $28 \%$, while those exceeding $50 \mathrm{~N}$ was $97 \%$, and those exceeding $60 \mathrm{~N}$ was $86 \%$. Taking these into consideration, we came to a conclusion that the handling force of the threshing drum cover opening lever should preferably be at 50 to 60
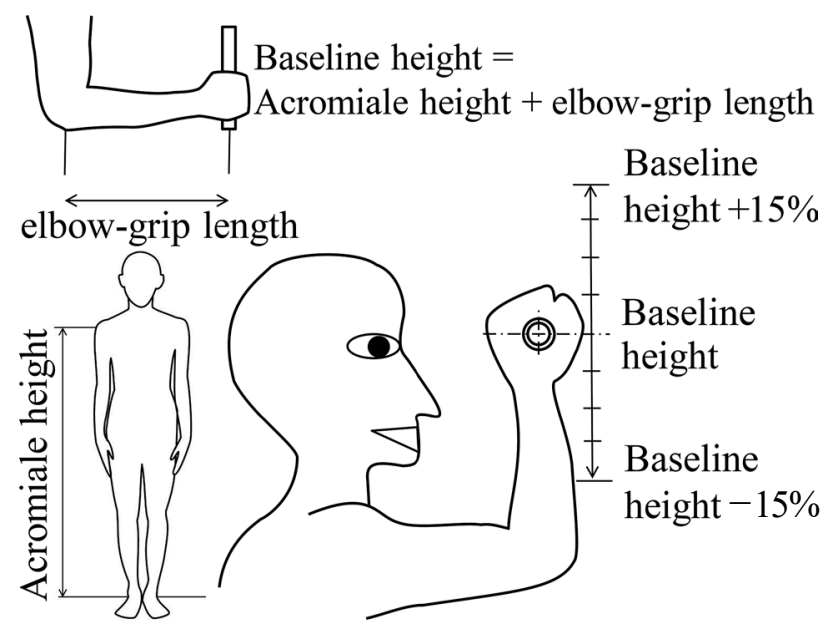

Fig. 2. Acromiale height, elbow-grip length, and zones of experiment

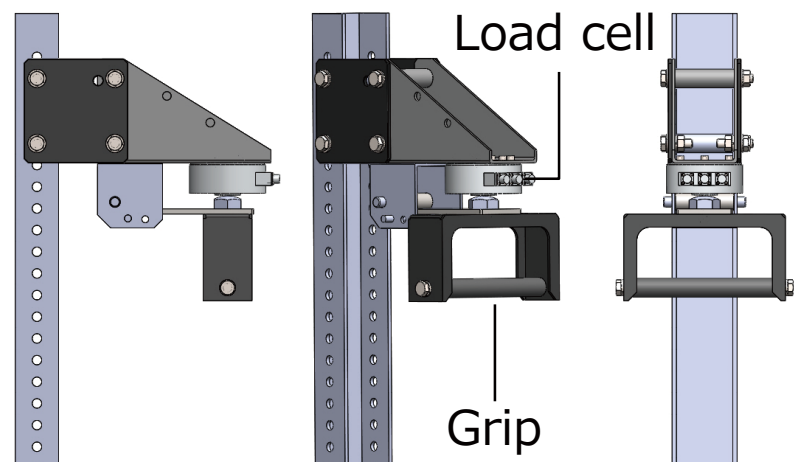

Fig. 3. A schematic diagram of the measuring device (From left: side view, perspective view, and front view)
$\mathrm{N}$ or below. Except for small type models such as tworow type, most commercialized models are equipped with threshing drum cover opening levers whose required handling force is $60 \mathrm{~N}$ or more, so we consider it would be difficult for female users to open the threshing drum cover under conventional handling force conditions (Fig. 4). The aforementioned questionnaire survey results also verify this measurement results by finding that as many as $55 \%$ of the respondents answered that they "pulled out by force" regarding the way to release the entangled hand. If the handling force of the threshing drum cover opening lever is lowered to the abovementioned level, however, it is probable that the threshing drum cover would be opened even during a normal harvesting work when the size of the mounted threshing drum is big. Also, about the position of the threshing drum cover opening lever equipped to commercialized models, the placement is rather high in case of big models, which presumably would be out of reach for some users. Manufacturers of head-feeding combines have claimed that regarding the production cost, construction that automatically releases hands that were entangled in the machine is lower than the construction which was made to solve the aforementioned problems. Therefore, we consider it necessary to be able to release the entangled hands without handling the threshing drum cover opening lever.

\section{Development of prototypes (Yamasaki 2017)}

\section{Setting of necessary conditions for development and development of prototypes}

In addition to abovementioned results, by reference to the safety standards of ISO (International Organization

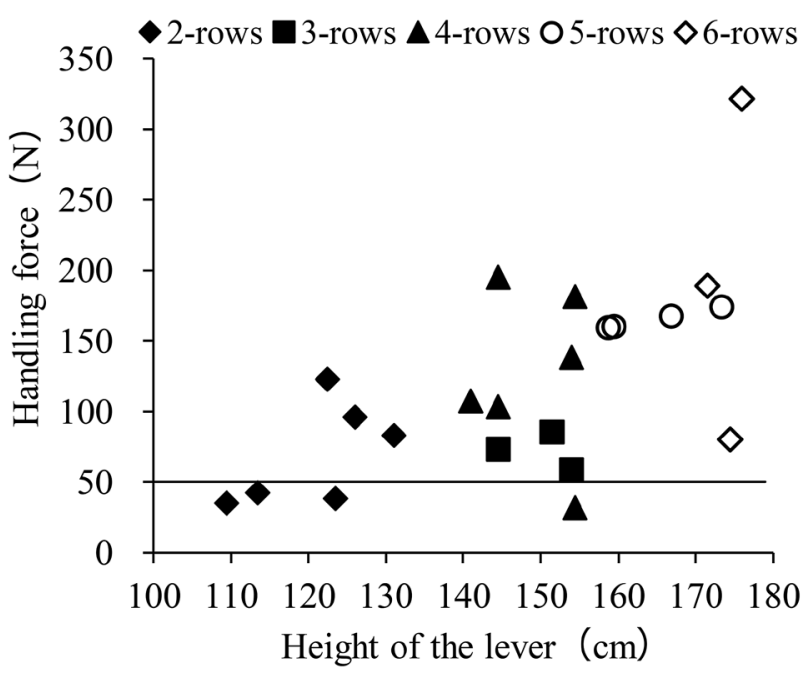

Fig. 4. Lever's height and the handling force of commercialized models of head-feeding combine harvesters 
for Standardization) and JIS (Japanese Industrial Standards), we set five necessary conditions for development of prototypes as follows:

(Condition 1) The braking distance of feed chain should be shorter than the distance between the points at which user's hand is sandwiched by the feed chain and the pinching rod (hereinafter referred to as pinching point) and the front end of the threshing teeth on the threshing drum (hereinafter referred to as baseline distance).

Reason: It is to avoid severe injury by stopping the feed chain before the entangled hand reaches the threshing drum.

(Condition 2) The emergency stop button should be secured with a setup so that the operation of the machine should not be resumed unless release operation is made.

Reason: It is to avoid restart of the engine by the operator on the driving seat at the time of power stop by the emergency stop button, due to his/her ignorance of an entanglement accident. In ISO13850:2006, in mention of the safety standards on emergency stop of machinery, it is stipulated as "Once active operation of emergency stop device have ceased following an emergency stop command, the effect of this command shall be sustained until it is manually reset"; "The emergency stop function shall be so designed that a decision to use the emergency stop device does not require the machine operator to consider the resultant effects."

(Condition 3) The emergency stop button should be colored red, and the background should be colored yellow.

Reason: It is to conform to the aforementioned safety standards ISO13850:2006: "The actuator of the emergency stop device shall be coloured RED. As far as a background exists behind the actuator and as far as it is practicable, the background shall be coloured YELLOW" by which differentiation with the body color should be easy.

(Condition 4) Either the threshing drum cover or pinching rod should be opened by manipulating the emergency stop button. The other way is to ensure handfed threshing work free from risk of involving hands.

Reason: In case of an entanglement of user's hand in hand-fed threshing work, an easy removal of the involved hand is made possible if the threshing chamber can be opened automatically.

(Condition 5) The emergency stop button should apply NC (Normally Closed) contact.

Reason: This condition conforms to JIS C8201-55:2008 (IEC 60947-5-5:2005) that stipulates requirements for the electrical emergency stop device of machinery, prescribing "all closed contact elements of an emergency stop device should be equipped with a positive actuation structure." In other words, this condition secures safety by requiring a structure with which the engine cannot be started in malfunction of an emergency stop device due to disconnection, etc.

Development of prototype head-feeding combine harvesters satisfying abovementioned conditions was carried out by using four different models of four to six rows (by four manufacturers in Japan, Model A, B, C, and D) as base models. In order to shorten the braking distance of the feed chain, for all models we separated braking mechanism of the feed chain from those of the engine (Fig. 5).

\section{Evaluation of the developed models}

We manufactured three different types of prototype machinery that satisfy the aforementioned conditions, namely, normal operation type, single handed control type, and two handed control type, while following structures as stated below.

Normal operation type (Models A and B): Hand-fed threshing is done following the conventional flow, and when the user presses the emergency stop button, the engine stops immediately and simultaneously the clutch equipped to the feed chain driving gear case is cut off, which stops the feed chain promptly. At the same time, the motor is activated to open either the threshing drum cover (for Model A) or the pinching rod (for Model B).

Single handed control type (Model C): The headfeeding combine harvester is set ready for hand-fed threshing by tilting the rice straws loading bar placed at hand-fed threshing unit to the front. The feed chain is activated only while the operator keeps pressing the button placed on the left of hand-fed threshing unit, and when the emergency stop button is pressed, HST (Hydro Static Transmission) for conveyer is shifted to the neutral position to stop the feed chain promptly. Moreover, a direct driven cylinder set to the threshing unit is activated upward by a motor to unlock the threshing drum cover, which action further opens the threshing drum cover using force of a gas spring and the aforementioned cylinder.

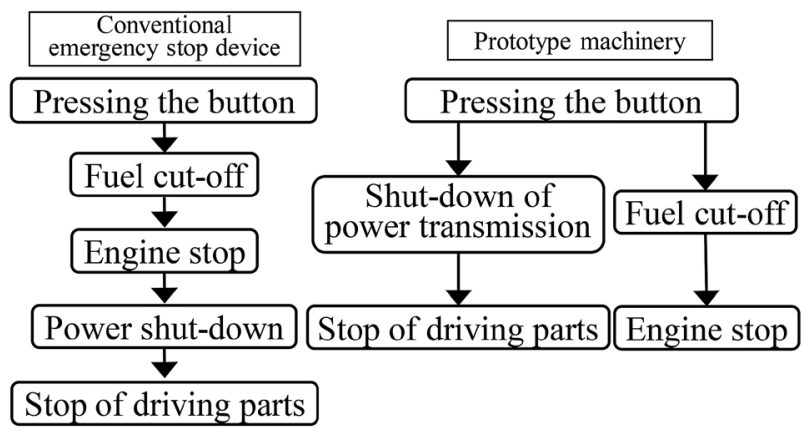

Fig. 5. Stopping flow diagram on a prototype machine 
Two handed control type (Model D): The feed chain is activated when the operator presses the hand-fed threshing operation handle hard against the feed chain over rice straws with the user's right hand while pressing the button placed on the left of hand-fed threshing unit with the user's left hand. The feed chain stops when the operator takes hands off either from the handle or the button.

We conducted measurement of the braking distance of the feed chain, along with evaluation of usefulness to evaluate these prototypes.

(1) Means of the test

As for definition of the pinching point, we took two aspects into consideration: when the portion covering from the palm to the shoulder is trapped into the feed chain, fingers shall be injured by the threshing drum; and the pinching point shall be closer in position to the threshing drum on the feed chain when the palm, thinner than the shoulder part, is trapped. Considering these two, and also using the value of $23.0 \mathrm{~mm}, 5 \%$ tile palm thickness of females 65 years of age and older (General Incorporated Association Research Institute of Human Engineering for Quality Life, Japan 1996), as well as the critical clearance of $20 \mathrm{~mm}$ for a human palm unable to pass through as prescribed in ISO13857:2008, we defined pinching point as "the position at which the distance between the horizontal part of the feed chain plate and lower end of the pinching rod is set $20 \mathrm{~mm}$ " (Fig. 6).

With regard to the braking distance of the feed chain $D_{B F C}(\mathrm{~mm})$, we applied the following formula to figure it out:

$$
D_{B F C}=R_{N} \times Z_{S} \times P_{C}
$$

where $R_{N}$ : the revolution number of the driving sprocket from manipulation of the emergency stop button until the complete stop of the feed chain, $Z_{S}$ : teeth number of the sprocket, and $P_{C}$ : chain pitch (mm).

Measurement of $R_{N}$ was done by using a rotational speed meter (EC-2100, Ono Sokki Co., Ltd.). The test

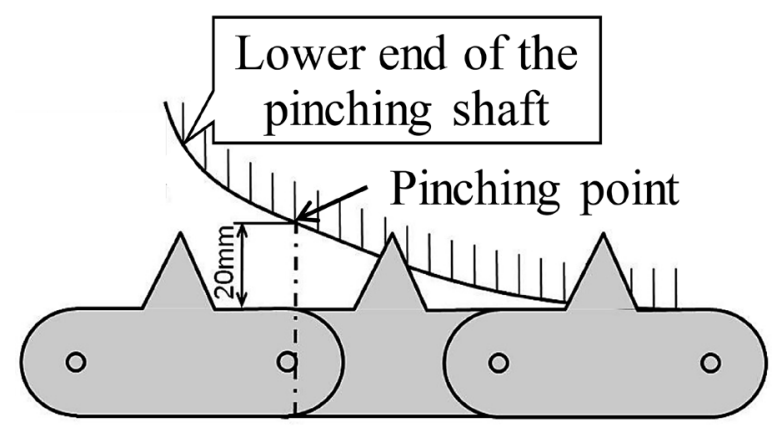

Fig. 6. Definition of pinching rod was carried out at rated engine speed for hand-fed threshing work in an unloading state, and the average value of three times measurement was picked up for the braking distance.

Usefulness was evaluated by conducting a hand-fed threshing work by applying rice straws.

(2) Results and considerations

Figure 7 shows the exterior of prototypes, and Table 6 shows specifications as well as elements on braking distance of feed chain. Due to separation of the braking mechanism for the feed chain from the one for the engine, and also due to reduction in conveying speed of the feed chain for hand-fed threshing work, braking distance of the feed chain was found to be shorter. We found it quite a significant reduction, as compared with a report that about 1.0 to $1.4 \mathrm{~m}$ of inertia motion of the feed chain was observed even after activation of the emergency stop device in case of large scale models greater than five rows and more (Okada et al. 2009). Moreover, due to extension of the baseline distance and other measures, for all models the remaining distance by the front end of the threshing drum showed positive values, while the maximum margin time before reaching to the front end of the threshing teeth on the threshing drum was shown $0.58 \mathrm{~s}$, satisfying Condition 1 (Table 7). Also, as for other conditions, we confirmed that visibility does not matter regardless of the body colors for Condition 3 , and that required functions activated normally for Conditions 2,4 and 5.

We developed about three types of mechanism to satisfy Condition 4, and we confirmed an easy removal of the involved hand that was made possible by adding an opening function of either the threshing drum cover or the pinching rod, by which it is presumed that severe injury is effectively prevented. We found some challenges in workability regarding single handed control of Model $\mathrm{C}$, in that rice straws should be conveyed alone with user's right hand, although the function to stop the feed chain worked efficiently with ease of handling by simply leaving the button when the user's hand is entangled. In case of Model D, indeed there was a concern of lower workability in exchange with no probability of pinching hands, but the decline of efficiency was not presumed to be so critical due to its ability to load a comparatively large amount of rice at a time.

\section{Provisions for the future}

Models A, B, and C that we developed in this study would be effective to avoid injury to be severe in handfed threshing work, but these models cannot prevent the injury itself. Model D, on the other hand, we consider as 

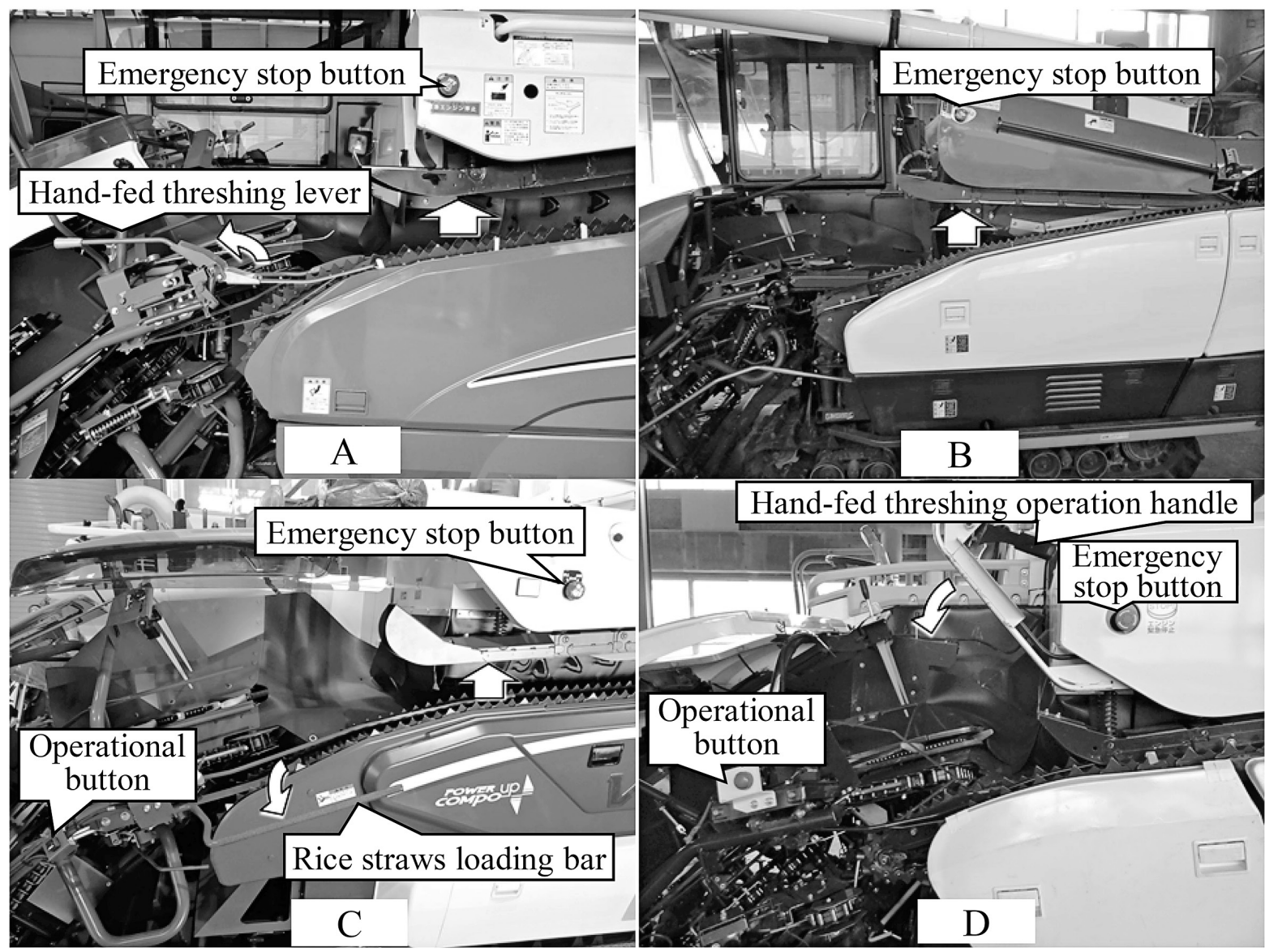

Fig. 7. Prototype threshing machines

Table 6. Specifications / elements on braking distance of the feed chain about prototype machines

\begin{tabular}{lccrr}
\hline \hline & A & B & C & D \\
\hline Number of rows & 6 & 4 & 6 & 5 \\
Rated output (kW) & 66.2 & 49.3 & 71.7 & 53.3 \\
Rated rotational frequency (rpm) & 2600 & 2700 & 2600 & 2200 \\
Rotational frequency in hand-fed threshing (rpm) & 1700 & 2430 & 2600 & 2200 \\
Drive system of the feed chain & Mechanical & Mechanical & HST & Mechanical \\
Existence of low speed mode of the feed chain & Positive & Positive & Negative & Positive \\
\hline
\end{tabular}

Table 7. Braking distance of feed-chain on prototype threshing machines

\begin{tabular}{lcrrr}
\hline \hline & A & B & \multicolumn{1}{c}{ C } & D \\
\hline Baseline distance $(\mathrm{mm})$ & 264 & 240 & 259 & 480 \\
Braking distance $(\mathrm{mm})$ & 100 & 146 & 67 & 226 \\
Remaining distance $(\mathrm{mm})$ & 164 & 94 & 192 & 254 \\
Conveying speed $(\mathrm{mm} / \mathrm{s})$ & 430 & 650 & 330 & 440 \\
\hline \multicolumn{1}{c}{ Margin time (s) } & 0.38 & 0.15 & 0.58 & 0.58 \\
\hline
\end{tabular}

being effective in reducing injury accidents due to its non-probability of involving hands. However, the handfed threshing work using this model should follow a methodology different from the conventional one, therefore some efforts and improvements would still be required to be acceptable for farmers in the process of familiarizing the model. Models of head-feeding combine harvesters equipped with the developed device are commercialized by four agricultural machinery manufacturers in Japan, and they spread more than 6,000 units of 21 models.

We consider that the best way to prevent hand-fed 
threshing accidents in the future is to develop a headfeeding combine harvester model that does not require any manual harvesting at four corners of a rice field. In case of any clogging in the process of conveying harvested rice, however, hand-fed threshing work is inevitable to handle rice straws that are removed out of the conveying unit, so measures to tackle this aspect are necessary, too. The second-best choice would be to take a preventative measure to stop the feed chain in advance by detecting the existence of a hand before entanglement. The study by Okada et al. (2016) reported on a device to detect a hand approaching the pinching point, by using a magnetic core coil or an impedance sensor while asking users to wear a pair of gloves using plastic magnets. For the future, we hope such technical measures would be soon put to practical use, and thereby injury of farmers be expired.

\section{References}

ISO 13850 (2006) Safety of machinery -Emergency stopPrinciples for design, International Organization for Standardization.

ISO 13857 (2008) Safety of machinery -Safety distances to prevent hazard zones being reached by upper and lower limbs, International Organization for Standardization.

Japan Institute of Rural Medicine (2003) Noukigu niyoru jikosaigai no jittai to sono yoboutaisaku ni tsuiteno kenkyu houkokusho (Research report about actual situations of accident by agricultural equipment and method to prevent accidents) [In Japanese].

JIS C8201-5-5 (2008) Low-voltage switchgear and controlgear -Part 5-5: Control circuit devices and switching elementsElectrical emergency stop device with mechanical latching function, Japanese Industrial Standards Committee.

Ministry of Agriculture, Forestry and Fisheries: Heisei 17 nen ni hassei shita nousagyoujiko no gaiyou (Outline of fatal farm work accidents in 17th year of the Heisei period) [In Japanese]. http://www.maff.go.jp/j/seisan/sien/sizai/s_kikaika/ anzen/pdf/h17ziko_gaiyo.pdf.

Ministry of Agriculture, Forestry and Fisheries: Heisei 28 nen ni hassei shita nousagyoujiko no gaiyou (Outline of fatal farm work accidents in 28th year of the Heisei period) [In Japanese]. http://www.maff.go.jp/j/press/seisan/sizai/attach/ pdf/180213-2.pdf.

Ministry of Health, Labour and Welfare: Roudou saigai toukei, sangyoubetsu sishou nensenninritsu, kyuhgyo yokka ijo (Statistics of workers' accident, rate of injuries and deaths per one thousand farmers, injuries should involve four days) [In Japanese]. http://anzeninfo.mhlw.go.jp/information/ h08_26_sen01.html.

Okada, S. et al. (2009) Heisei 20 nendo shiken kenkyu seiseki (Report of examination and research on 20th year of the Heisei period in the Japanese calendar), 29, Institute of Agricultural Machinery, Saitama [In Japanese].

Research Institute of Human Engineering for Quality Life (1996) Human Body Dimensions Data for Ergonomic Design. HQL, Osaka.

Tomita, M. et al. (2013) Current Design and Ergonomics of Agricultural Machinery and Its Suitability for Use by Elderly and Female Operators. JSFWR, 48, 21-27 [In Japanese with English summary].

Tomita, M. et al. (2015) Analysis of Accidents on Head-feeding combine harvesters with Questionnaire Survey for Japanese Farmers. JSFWR, 50, 11-20 [In Japanese with English summary].

Yamasaki, H. et al. (2016) Development of Emergency Stop Device for the Hand-Fed Threshing on Head-Feeding Combine (Part 1) A Survey into Hand-Fed Threshing and Development of a Prototype Model. Journal of JSAM, 78, 248-256 [In Japanese with English summary].

Yamasaki, H. et al. (2017) Development of Emergency Stop Device for the Hand-Fed Threshing on Head-Feeding Combine (Part 2) Force of Vertical Lifting by Women and Development of a Final Model. Journal of JSAM, 79, 310316 [In Japanese with English summary]. 